\title{
Engajamento discente em um ambiente virtual de aprendizagem
}

\author{
Luciana Nunes Viter
}

Fundação de Apoio à Escola Técnica

\begin{abstract}
Resumo
Esta pesquisa pretendeu investigar o engajamento discente nas interações em um ambiente virtual de aprendizagem (AVA) de um curso semipresencial, a partir do ponto de vista dos participantes. O referencial teórico foi construído a partir de estudos sobre engajamento em contextos educacionais e um estudo de caso de natureza etnográfica foi desenvolvido no contexto de uma disciplina de graduação destinada ao ensino de inglês para fins específicos. Os dados foram gerados por estudantes e professores do curso em fóruns de discussão on-line, questionário, entrevistas e em um grupo focal on-line. Os resultados identificaram fatores relevantes que favoreceram ou dificultaram o engajamento discente nas interações on-line propostas e as conclusões apontaram implicações e contradições significativas entre as percepções e ações dos participantes.
\end{abstract}

Palavras-chave: Engajamento discente, ambiente virtual de aprendizagem, educação on-line.

\begin{abstract}
This research aimed to investigate student engagement on interactions in a virtual learning environment (VLE) of a blended learning course from the participants' point of view. The theoretical foundation was built from studies about engagement in educational contexts, and a case study of an ethnographic nature was developed in the context of an undergraduate discipline aimed at teaching English for specific purposes. Data were generated by students and teachers from the course in online discussion forums, questionnaire, interviews and in an online focus group. The results identified relevant factors that hampered or favored the student's engagement in the online interactions proposed and the conclusions pointed significant implications and contradictions between the participants' perceptions and their actions in the virtual learning environment of this blended online course.
\end{abstract}

Keywords: Student engagement, virtual learning environment, online learning.

\section{INTRODUÇÃO}

Para além da mera utilização de artefatos tecnológicos, as últimas décadas parecem ter transformado as características e necessidades dos estudantes, o que é 
atribuído, em grande parte, à explosão das tecnologias de informação e comunicação, conforme descreve Belloni (2002):

As novas gerações estão desenvolvendo novos modos de perceber (sintéticos e "gestaltianos" em contraposição aos modos analíticos e sequenciais trabalhados na escola), novos modos de aprender mais autônomos e assistemáticos ("autodidaxia"), voltados para a construção de um conhecimento mais ligado com a experiência concreta (real ou virtual), em contraposição à transmissão "bancária" de conhecimentos pontuais abstratos, frequentemente praticada na escola. (BELLONI, 2002, p. 120)

Diante deste cenário, há concordância entre estudiosos de que é necessário compreender melhor essas transformações e investigar como promover o engajamento desses alunos em sua aprendizagem nesses novos cenários (OBLINGER e OBLINGER, 2005; PARSONS e TAYLOR, 2011; RUDDUCK, 2007). Porém, constata-se que suas perspectivas ainda encontram-se bastante ausentes da literatura sobre engajamento (PARSONS e TAYLOR, 2011), o que encoraja e justifica o aprofundamento de pesquisas sobre o tema.

Assim sendo, os objetivos que impulsionaram a elaboração do presente trabalho, um estudo de natureza etnográfica recortado da dissertação de mestrado da autora, foram contribuir para a identificação dos elementos que possam influenciar negativa ou positivamente no engajamento em ambientes virtuais de aprendizagem e colaborar para o aprimoramento dos formatos desses ambientes e dos resultados de sua utilização. Com essa finalidade, optou-se por investigar os fatores que favoreceram ou obstaram o engajamento nas interações digitais quando da oferta de uma disciplina de ensino de língua inglesa para fins específicos em um curso de graduação, a partir do discurso de seus participantes.

Tendo em vista que se desejava pesquisar práticas sociais e culturais em um grupo específico de indivíduos, optou-se pela realização de um estudo de caso de natureza etnográfica com o objetivo de apreender a cultura, os valores e o modus operandi da comunidade investigada, privilegiando os pontos de vista de seus integrantes (ANGROSINO, 2005; YIN, 2009). A partir dessa perspectiva êmica, almejou-se compreender os fatos sociais a partir da ótica de quem os experimenta, valorizando suas vozes a fim de obter uma compreensão mais aprofundada e holística do tema investigado. 


\section{ENGAJAMENTO EM CONTEXTOS EDUCACIONAIS}

O conceito de engajamento é comumente associado ao relacionamento ativo do indivíduo com a tarefa e com o contexto que a envolve, sendo consenso que ele é necessário para resultados positivos na aprendizagem (HARRIS, 2008; PARSONS e TAYLOR, 2011; DUNLEAVY; MILTON, 2009). No entanto, a literatura sobre o tema demonstra o quanto pode ser problemático definir os limites terminológicos do termo (HARRIS, 2008; ATWEH; BLAND; CARRINGTON; CAVANAGH, 2007) e avaliar os níveis de engajamento discente (PARSONS e TAYLOR, 2011).

O engajamento destacou-se como foco de investigação a partir dos anos 80, inicialmente buscando responder questões relacionadas às desigualdades nos resultados acadêmicos das diversas populações de estudantes (HARRIS, 2008). Tradicionalmente o engajamento era analisado de forma descontextualizada e individualista (ZYNGIER, 2007), como algo que dependia exclusivamente da organização das práticas dos estudantes pelos professores, sem levar em conta outros possíveis fatores que pudessem estar envolvidos no contexto educacional. Posteriormente, os estudos sobre engajamento deslocaram seu foco das estratégias docentes para se concentrarem em como os estudantes aprendem melhor, passando a priorizar processos ao invés de resultados (CLAXTON, 2007). Novas investigações sobre o tema fizeram emergir diferentes percepções sobre o conceito de engajamento por parte de estudantes e professores e critérios qualitativos diversificados para sua avaliação nos processos de aprendizagem (PARSONS e TAYLOR, 2011).

Buscando ampliar a compreensão sobre o tema e estruturar possíveis critérios para sua mensuração em contextos educacionais, diversas propostas para categorização do engajamento foram apresentadas, algumas sobrepostas entre si. Acadêmico, cognitivo, intelectual, institucional, emocional, afetivo, comportamental, social e psicológico são apenas algumas das tipologias descritas para o engajamento, segundo extensa revisão bibliográfica elaborada por Parsons e Taylor (2011). Um dos padrões mais frequentemente adotado na literatura foi o proposto por Fredricks, Blumenfeld e Paris (2004), que após analisarem diversos estudos caracterizaram o engajamento como comportamental, cognitivo e emocional, conforme descrito a seguir. 


\section{Engajamento comportamental}

Associado a comportamentos mais facilmente observáveis como a participação efetiva do estudante nas atividades curriculares e extracurriculares propostas, o engajamento comportamental costuma ser tradicionalmente mensurado a partir de aspectos quantitativos, como frequência, eficácia e tempo despendido na realização de atividades e notas obtidas em testes.

Referindo-se a aspectos comportamentais, Harris (2008) chega a afirmar que a visão de engajamento por parte de alunos e professores frequentemente restringe-se à mera atuação dos estudantes nas tarefas acadêmicas ao invés de priorizar o alcance efetivo de metas de aprendizagem. Essa perspectiva aparentemente supõe que o aprendizado é resultado implícito da participação do aluno nas atividades desenvolvidas.

Entretanto, investigação levada a cabo pela mesma autora revela que estudantes demonstraram comportamentos aparentemente engajados e obtiveram sucesso em componentes acadêmicos, sem de fato se sentirem ou se declararem interessados nos processos e metas de aprendizagem que lhes correspondiam (HARRIS, 2008). Mesmo estudantes que pelos padrões tradicionais são considerados engajados, revelam que na maior parte do tempo agem motivados por fatores que pouco ou nada se relacionam a sua aprendizagem, fazendo apenas o que julgam necessário fazer para obter boas notas (DUNLEAVY e MILTON, 2009).

Essas constatações sugerem que priorizar meramente aspectos comportamentais observáveis e dados quantitativos para mensurar o engajamento do estudante, como comumente ocorre nos contextos escolares, não responderá por avaliar efetivamente seus níveis de aprendizagem (PARSONS e TAYLOR, 2011), apesar da importância dessas referências quando inseridas dentro de contextos que também levem em conta outros aspectos.

\section{Engajamento cognitivo}

Representado pelo investimento pessoal, deliberado, persistente e autônomo do aluno em sua aprendizagem, o engajamento cognitivo mobiliza habilidades cognitivas mais complexas como a capacidade de analisar, comparar e avaliar, utilizadas com o objetivo de aumentar a própria compreensão, resolver problemas complexos e construir 
novos conhecimentos, desenvolvendo estratégias específicas para os fins que se pretenda atingir (FREDRICKS, BLUMENFELD e PARIS, 2004).

O engajamento cognitivo aparentemente se relaciona de modo mais próximo com a aprendizagem e comumente é o tipo de engajamento mais valorizado por autores que propõem classificações hierarquizadas para o engajamento (FINN, 1989; NYSTRAND e GAMORAN, 1991). Segundo Fredricks, Blumenfeld e Paris (2004), é mais provável que haja maior nível de engajamento cognitivo por parte dos estudantes quando os professores propõem tarefas estimulantes e desafiadoras sob o ponto de vista intelectual e que se relacionem às suas vidas fora do ambiente acadêmico, oferecendo assim oportunidades para que os estudantes desenvolvam e exponham suas próprias ideias.

Quando comparado ao engajamento comportamental, o engajamento cognitivo inclui aspectos mais internalizados e mais dificilmente observáveis como a percepção da relevância da própria aprendizagem e o desenvolvimento de metas pessoais e da autonomia do estudante (APPLETON, 2006). No caso do presente trabalho, construído a partir de uma perspectiva etnográfica, buscou-se enfatizar a mensuração de indicadores do engajamento a partir da análise qualitativa dos discursos dos participantes da investigação: alunos e professores do curso.

\section{Engajamento emocional}

O sentimento de pertencer a um grupo e de ser representado pela comunidade de aprendizagem e pela instituição educacional, assim como a aceitação de seus valores, são as principais referências para identificação desse tipo de engajamento. Considera-se que existe engajamento emocional quando os estudantes apresentam atitudes e reações positivas em relação à instituição, aos professores, ao aprendizado e aos seus pares (HARRIS, 2008). Nesse sentido, Rudduck (2007) salienta a importância de que o aluno sinta que faz parte de uma comunidade de aprendizagem e que sua participação agrega valor ao resultado final a ser obtido, para que haja maior engajamento de sua parte. Meyer e Turner (2006) acrescentam que:

O engajamento do aluno na aprendizagem requer experiências emocionais positivas, que contribuam como alicerce para os relacionamentos entre professor e estudante e para as interações necessárias para sua motivação em aprender (MEYER e TURNER, 2006, p. 377). 
Embora reconhecendo os desafios de se tentar medir componentes emocionais do engajamento na aprendizagem, uma vez que estes dizem respeito a processos internalizados e pessoais, de modo semelhante ao que ocorre no engajamento do tipo cognitivo, estudos passaram a valorizar mais o empenho do estudante, seu senso de competência e o apoio que oferece e aceita de seus pares, entre outros dados relacionados a aspectos emocionais, para avaliar seu engajamento (DUNLEAVY e MILTON, 2009).

\section{Condições necessárias ao engajamento discente}

Os resultados do engajamento, por sua própria natureza, dependem dos múltiplos fatores que o constituem, não sendo, necessariamente, fruto da ação ou da intervenção em um único de seus aspectos, mas produto das contribuições e esforços de seus participantes em suas diversas dimensões (TROWLER, 2010, p. 42). No entanto, embora a instituição e o professor normalmente não sejam capazes de interferir de forma direta em circunstâncias externas potencialmente negativas para o engajamento discente, cabe-lhes construir ambientes encorajadores e adotar ações que facilitem e estimulem o engajamento discente (FLOYD; HARRINGTON; SANTIAGO, 2009; PATRICK; RYAN; KAPLAN, 2007; REEVE, 2012).

Desse modo, quando do planejamento e implementação de propostas pedagógicas, é importante buscar assegurar condições específicas que possam vir a favorecer o engajamento nos processos de aprendizagem, ainda que estas não possam ser levadas em conta de forma isolada (PARSONS e TAYLOR, 2011). Uma delas é considerar a adequação da tarefa proposta às possibilidades do aprendiz de realizá-la e de superar os desafios que ela possa vir a propor (APPLETON; CHRISTENSON e FURLONG, 2008). Outra é avaliar a percepção por parte dos estudantes de que a atividade que deve realizar é significativa e relevante, o que ocorre com frequência quando a proposta apresentada envolve questões da vida real (HARRIS, 2008; FREDRICKS; BLUMENFELD e PARIS, 2004).

Relacionamentos mais abertos e colaborativos entre professor e aluno também contribuem para o engajamento emocional por parte dos discentes, principalmente quando a participação ativa e a autonomia do estudante são incentivadas (RUDDUCK, 2007). Essa concepção participatória da aprendizagem inclui os professores que 
priorizam o acompanhamento e incentivo aos processos diretamente relacionados à aprendizagem para só depois priorizar os resultados (PARSONS e TAYLOR, 2011).

Os resultados da investigação realizada por Dunleavy e Milton (2009), que indagou dos discentes qual seria o tipo de ambiente de aprendizagem que mais estimularia seu engajamento, também comprovam a importância da interação e da colaboração nesses contextos. Nesse estudo, as três características mais frequentemente identificadas pelos estudantes foram: ter oportunidades para aprender com os seus pares e com a comunidade, para interagir com aqueles que fossem mais experientes e para ter mais diálogo, de modo geral.

É interessante observar que, embora a oferta de recursos materiais e tecnológicos que possam enriquecer os fazeres pedagógicos também contribua para aumentar os níveis de engajamento, nesse particular, professores e alunos atribuem maior valor aos aspectos humanos envolvidos nos processos de ensino-aprendizagem (PARSONS e TAYLOR, 2011).

\section{METODOLOGIA DE PESQUISA}

O contexto de investigação foi o ambiente on-line utilizado por um curso de inglês para fins específicos cuja principal proposta era o desenvolvimento de competências para leitura de textos acadêmicos em inglês. A professora, experiente na modalidade de ensino a distância e no uso de recursos digitais, utilizou um ambiente virtual de aprendizagem (AVA) construído a partir do aplicativo Moodle ${ }^{1}$, para as atividades on-line de seu curso, em caráter complementar às atividades presenciais, auxiliada por uma monitora que era professora de línguas em formação. A plataforma digital utilizada para a construção do AVA foi provida pelo Projeto Letras 2.0, desenvolvido desde 2010 pelo Núcleo de Pesquisa em Linguagem, Educação e Tecnologia (LingNet) da Universidade Federal do Rio de Janeiro (UFRJ), a fim de oferecer à comunidade da Faculdade de Letras da UFRJ condições de acesso a iniciativas educacionais mediadas pelas novas tecnologias, propiciar a oferta de cursos na modalidade on-line com uso da plataforma Moodle e criar oportunidades para o desenvolvimento de pesquisas e para a formação de docentes que atuem nessa modalidade (TAVARES, 2014).

\footnotetext{
${ }^{1}$ O Moodle é um pacote de aplicativos para construção de ambientes virtuais de aprendizagem, sendo atualmente o programa de seu gênero mais utilizado no mundo (MOODLE PTY LTD, 2014).
} 
A carga horária do curso, oferecido aos alunos de graduação de biologia, foi distribuída ao longo de um semestre e estruturada em caráter semipresencial, sendo proposta inicial da professora responsável que metade das aulas fosse on-line e metade presencial. Entretanto, razões relacionadas ao calendário acadêmico determinaram um número de aulas à distância superior ao de aulas presenciais. Assim sendo, o curso investigado totalizou sete aulas (encontros) presenciais e dez aulas (encontros) a distância, estas distribuídas em doze diferentes tópicos organizados no ambiente digital.

A principal questão que este trabalho buscou responder foi quais fatores e aspectos dificultaram e quais favoreceram o engajamento dos alunos nas interações propostas no ambiente virtual de aprendizagem do curso semipresencial, a partir dos pontos de vista dos participantes. Para geração de dados, foram utilizados um grupo focal on-line e um questionário presencial (com participação exclusiva dos alunos), entrevistas presenciais (com participação exclusiva da professora e da monitora) e registros nos fóruns on-line do curso (com participação dos alunos, da professora e da monitora). $\mathrm{O}$ uso desses instrumentos possibilitou acesso a diferentes perspectivas dos participantes a respeito da utilização do ambiente on-line, contribuindo para uma visão mais abrangente dos temas investigados.

Visando preservar as identidades dos participantes, nas transcrições dos dados foram utilizados nomes fictícios ou genéricos para identificar os seus autores. É importante registrar ainda que a seleção dos dados textuais obtidos foi organizada a partir de sua contextualização com os tópicos abordados, não tendo os referidos dados sofrido nenhum tipo de alteração ao serem transcritos, exceto eventuais grifos da pesquisadora com o fim de ressaltar algum aspecto no trecho citado.

A partir dos dados gerados foram destacados e categorizados os elementos dos discursos dos participantes considerados relevantes para os objetivos da pesquisa. Essas categorias foram construídas a partir de percursos circulares de análise e interpretação dos dados, nos quais os resultados foram verificados e comparados entre si, e agrupadas em fatores e aspectos favoráveis ao engajamento e fatores e aspectos desfavoráveis ao engajamento, ora apresentados. Dessa forma, as categorias de análise surgiram dos próprios dados, a partir das ênfases e destaques mais frequentes ou mais específicos observados nos discursos dos participantes, não se baseando as mesmas em categorizações preexistentes. 


\section{Fatores e aspectos favoráveis ao engajamento}

A maioria dos estudantes avaliou positivamente a utilização dos recursos da plataforma virtual, com destaque para as facilidades oferecidas pelo sistema para as interações on-line, reconhecendo vantagens como a flexibilidade de horário proporcionada pela mediação digital:

$\mathrm{O}$ acesso pelo Moodle facilitou as interações (Aluno(a) que preferiu não se identificar, questionário).

$\mathrm{O}$ fato de nem todas as atividades serem realizadas em sala de aula ajudou bastante, porque a imposição de um tempo para realizá-las em aula sempre seria menor (Wilson, questionário).

Entretanto, visto a natureza do curso, o vínculo quase constante com o ambiente virtual foi eficiente no aprendizado (Laerte, grupo focal).

Outro fator que os alunos destacaram como dos mais positivos para seu engajamento no curso foi a facilidade para a interação digital com as participantes docentes. Além de creditarem essa abertura às posturas pessoais da professora e da monitora do curso, os estudantes também a relacionaram à utilização das ferramentas digitais do AVA, conforme pode ser observado nos excertos transcritos a seguir:

Enfim, parabéns à professora e à monitora, que sinceramente, ambas foram das mais solícitas que eu já tive. Acho que se não tivemos maior dificuldade com as inúmeras coisas diferentes apresentadas na matéria, foi por causa da paciência e atenção que elas tiveram. De verdade! (Amanda, grupo focal).

Pudemos contar com a ajuda da professora e da monitora a todo o tempo. Podíamos sanar qualquer dúvida em curto período de tempo através do moodle e por e-mail, o que foi de extrema importância para a realização das atividades (Amanda, questionário).

As diversas possibilidades de interação mútua proporcionadas pelo desenho do curso e pelo uso do componente digital também foram vistas de forma positiva pelos estudantes, assim como a possibilidade de se comunicarem de modo mais informal no contexto on-line.

Pudemos trocar informações e experiências em nossas diferentes áreas ao vivo e online. Um aspecto importante foi a troca de forma descontraída (Cleonice, questionário).

Foi bastante fácil interagir com todos, o que facilitou as trocas de informações e execuções de trabalhos (Aluno(a) que preferiu não se identificar, questionário). 
Achei muito interessante poder discutir determinados assuntos (como gênero e sexualidade) e observar diferentes pontos de vista, muitos dos quais nunca tinha nem parado pra refletir (Renata, grupo focal).

A fluidez e a variedade identificadas nas comunicações pela maioria dos participantes no contexto on-line contribuíram para que o grupo percebesse o curso como um contexto bastante "interativo", de modo geral, o que também foi visto pelos estudantes como característica benéfica ao aprendizado:

Os diferentes tipos de interação ajudaram a aumentar o interesse pelo conteúdo (Aluno(a) que preferiu não se identificar, questionário).

Também foi cumprida a proposta de fazer uma disciplina interativa tanto nas aulas presenciais quanto nas aulas online (Davi, grupo Focal).

A professora responsável pela disciplina optou por trabalhar com gêneros textuais que considerou mais relevantes para a área, após consultar os alunos participantes, buscando propor estratégias de leitura e análises de elementos linguísticodiscursivos que pudessem facilitar a compreensão desses textos. Assim, o desenho instrucional do curso foi organizado pela professora em torno dos gêneros textuais identificados como significativos pelos estudantes no início do curso, buscando atender às suas necessidades específicas e propiciar a participação ativa dos estudantes no planejamento, estratégias que visavam favorecer o engajamento discente.

Além disso, a docente responsável pela disciplina apresentou as atividades relacionadas aos vários tipos de textos em diversos formatos. Essa diversidade dos temas tratados e de formatos de apresentação de conteúdos do curso agradou aos alunos, principalmente pelas oportunidades oferecidas para que interagissem de forma diferenciada do habitual em relação às suas práticas didáticas a respeito de tópicos relevantes para sua formação.

As atividades propostas foram bastante interessantes, levaram ao desenvolvimento de uma nova percepção sobre elementos tão comuns em nossa área, como por exemplo: artigos científicos, notícias e wikipedia. O resultado de todas essas atividades certamente contribuiu para nossa formação profissional. (...) Enfim, confesso que o Inglês Instrumental I superou as minhas expectativas!!” (Aída, grupo focal).

Os diferentes tipos de formatos de atividades tornam-se bastante eficazes no aprendizado (Wilson, questionário).

O curso foi bem estruturado e permitiu a realização de atividades bem diversificadas (Aluno(a) que preferiu não se identificar, questionário). 
A interdisciplinaridade dos temas tratados, deliberadamente buscada pela professora do curso a partir da escolha dos conteúdos utilizados, também foi vista como positiva pelos estudantes, assim como a utilização de práticas pedagógicas e de recursos didáticos diversos dos mais convencionais, incluindo-se neste particular o próprio uso do componente on-line:

Gostei da proposta da disciplina, uma vez que nos leva a discutir questões que não trabalhamos normalmente em outras disciplinas, como a interpretação e a compreensão de textos e artigos. (...) O curso me acrescentou em muito e espero que a professora continue com a gente em inglês II (Carmem, grupo focal).

A proposta da disciplina é bem interessante. A ideia de levar o aluno a um conhecimento que é construído aos poucos por intermédio de diferentes componentes (Lara, grupo focal).

As aulas foram muito interativas, muito diferentes do que temos em nosso curso! Pudemos questionar, expressar nossas opiniões, errar e acertar! Resumindo, eu achei bem legal o fato de termos aulas online. A gente não tem isso e na minha opinião, foram muito proveitosas! Sem contar que de vez em quando uma coisinha diferente do normal é sempre bem-vinda! (Amanda, grupo focal)

Os conteúdos mais proveitosos, em minha opinião, foram as discussões em fórum, upload de atividades e elaboração de questões por serem coisas novas e mais diferentes na forma de didática (Aluno(a) que preferiu não se identificar, questionário).

Quanto mais atividades diferentes, maior o interesse pelos assuntos (Aluno(a) que preferiu não se identificar, questionário).

A preocupação com a qualidade, variedade e especificidade dos materiais didáticos utilizados no componente on-line nortearam as escolhas de estratégias de ensino-aprendizagem adotadas no curso, no qual a professora responsável procurou adequar recursos e suportes ao contexto virtual:

Incomoda postar textos em formato .doc, pois o ambiente fica parecendo apenas uma pasta de arquivos. [...] Gostaria de dominar mais recursos para usar nos componentes on-line dos meus cursos, para eles ficarem mais com cara de curso "on-line" (Professora, entrevista).

Apesar de algumas objeções por parte dos alunos, a atribuição de notas a todas as atividades on-line, que pressupunha a obrigatoriedade da realização dessas tarefas a serem apresentadas em formato portfolio ao final do curso, foi identificada pela maioria dos estudantes como favorável ao engajamento nas atividades, assim como pela professora e monitora do curso. 
Cada atividade on-line individualmente não tinha um valor muito alto, geralmente não passando de meio ponto. Mas se não valesse nota, os alunos não teriam feito, com exceção do fórum "Food for thought" (Monitora. entrevista) (grifo meu)

Desse modo, prevaleceu entre os participantes a visão de que a avaliação contínua das atividades digitais, entre outros fatores e aspectos, contribuiu para que os alunos se engajassem de modo mais comprometido com as tarefas propostas no ambiente virtual. No entanto, diante da perspectiva crítica apresentada pelos estudantes quanto ao volume das atividades, considerado quase unanimemente como excessivo por parte considerável dos participantes, é razoável supor que o engajamento estimulado por essa obrigatoriedade do cumprimento das atividades tenha sido basicamente do tipo comportamental, centrado principalmente na obtenção de notas ao final da disciplina.

\section{Fatores e aspectos desfavoráveis ao engajamento}

Houve quem mencionasse sua pouca familiaridade com a utilização de recursos tecnológicos ou apontasse dificuldades técnicas específicas com o manejo de determinados ferramentas digitais como obstáculos para a interação on-line e para a realização das tarefas propostas, questão relativamente comum em AVAs segundo Leffa (2005) e Franco (2009).

Eu achei a disciplina, apesar de um pouco trabalhosa (pela minha limitação com a internet) bem interessante (Carla, grupo focal).

Estou perdendo meu tempo, tentando atualizações de pdf reader e maneiras alternativas de fazer esse trabalho. Vou fazer do jeito que sair, não tem outra maneira. Vamos ver se conseguimos, em ingles II ter aulas e não brigas com o pc (Carmem, fórum de dúvidas do tópico "Artigos científicos").

Esses relatos questionam o conceito de nativos digitais proposto por Prensky (2001) que apresenta os membros das novas gerações como nativamente dotados para o uso dos recursos das novas tecnologias, ao menos como realidade absoluta. Porém, os depoimentos também demonstram que mesmo esses participantes reconheceram que essas dificuldades não eram a tônica geral do grupo, formado, em sua maioria, por jovens estudantes universitários, com faixa etária entre 19 a 25 anos, constituindo-se em usuários habituais de ferramentas digitais de comunicação. 
Como não sou uma grande fã de computadores, gostaria de ter mais aulas presenciais e menos aulas virtuais, mas acredito que poucos concordariam comigo (Carmem, grupo focal).

A maioria usa o computador com certa facilidade. Só uma aluna disse que não tinha computador, que não tem facebook, que não usa, que só estava entrando na internet quando estritamente necessário, para esta matéria (Monitora, entrevista).

Uma aluna propôs inclusive, no grupo focal on-line, que a participação digital não devia ser obrigatória. Essa aluna é bem diferente da maioria, pois costuma escrever seus trabalhos à mão para só depois digitar, tal é sua resistência ao computador. Não gosta de computador e não participa de rede social. Eu não esperava encontrar esse tipo de resistência. (...) A gente acha que os mais velhos terão mais resistência ao on-line (Professora, entrevista).

Um dos alunos apontou ainda a própria mediação on-line como fator desfavorável ao engajamento nas interações, considerando que a comunicação digital é bem mais limitada do que a presencial. É inegável que na comunicação mediada por computador (CMC) alguns canais característicos da comunicação face a face, como a linguagem corporal, não estão presentes. Por isso, comumente, busca-se superar esse tipo de desvantagem da comunicação mediada por computador (CMC) em relação à presencial com o uso de elementos paralinguísticos como os emoticons, convenções construídas para representar emoções faciais com caracteres do teclado (FRAGOSO; RECUERO e AMARAL, 2011). Recursos como o uso de fotos e informações complementares nos perfis também visam minimizar certo distanciamento característico das interações on-line.

Porém, mais do que demarcar caracterizações da comunicação eletrônica, essa perspectiva do participante também aponta para a necessidade de que estejam presentes elementos como a noção de pertencimento e as atitudes positivas em relação ao grupo, para que o aluno se engaje emocionalmente nas atividades de aprendizagem propostas (DUNLEAVY e MILTON, 2009; HARRIS, 2008).

A interação aluno-aluno foi muito ruim para mim. Achei muito confuso e não produtivo. (...) As discussões em fórum foram a pior parte. Não gosto de discussões on-line, pois não tem como saber quando alguém está sendo ofensivo ou não e assim é impossível manter uma discussão saudável (Aluno(a) que preferiu não se identificar, questionário).

A integração entre os componentes on-line e presencial do curso foi vista como potencialmente positiva pela maioria dos estudantes pela agilidade proporcionada à comunicação. Porém, em alguns momentos, essa interpenetração das duas esferas do 
curso também confundiu os estudantes, talvez porque estes fossem pouco habituados ao uso de uma plataforma digital de ensino-aprendizagem:

Tenho que admitir que o componente virtual combinado com o presencial me confundiu um pouco no início, pois no sistema pedia para imprimir e levar algo para a sala de aula, e outras vezes começamos uma atividade em aula que deveria ser terminada online (Lara, grupo focal).

Ademais, algumas dificuldades constatadas na dosagem das proporções entre presencial e on-line, no contexto investigado, se mesclaram à rejeição inicial manifestada à proposta de ensino semipresencial da disciplina. Essas perspectivas emergiram a partir de observações dos alunos a respeito do assunto, ainda que estes não tivessem experiência prévia com a modalidade:

\footnotetext{
No início houve uma resistência grande dos alunos, e alguns vieram falar comigo pedindo, por favor, para não terem que participar on-line (Professora, entrevista).

Não gosto muito do ambiente on-line. Prefiro aulas presenciais (Aluno(a) que preferiu não se identificar, questionário).
}

A maioria dos alunos do curso, mesmo reconhecendo positivamente aspectos como a facilidade para interações pelo uso de um componente on-line, deixou claro que não prescinde da mediação mais direta do professor quando da apresentação de conteúdos, procedimento que associam à interação presencial com o docente da disciplina:

As atividades feitas e discutidas em sala de aula foram mais proveitosas. Porque a interação pessoal professor-aluno é fundamental para facilitar a aprendizagem e a capacidade de discussão (Aluno(a) que preferiu não se identificar, questionário).

Na minha opinião, as aulas presenciais geraram maior resultado no aprendizado (Aluno(a) que preferiu não se identificar, questionário).

Tal informação confirma a perspectiva de Anderson (2003) a respeito da interação aluno-professor, quando a considera a mais prezada pelos estudantes dentre todos os tipos de interação em um ambiente digital de ensino-aprendizagem.

Outra posição destacada pelos alunos quando se manifestaram sobre o curso no grupo focal on-line, referiu-se à dimensão e à natureza das atividades propostas, consideradas inadequadas pela maioria dos estudantes:

A disciplina realmente nos demandou bastante tempo. Muitas vezes as atividades online semanais consumiam mais tempo do que aquele que costumamos dedicar às outras matérias (Laerte, grupo focal). 
Vou concordar com voces, mesmo a parte virtual sendo em teoria mais cômoda porque teriamos mais tempo para finalizar as tarefas e tirar dúvidas, na realidade ficou meio puxado (Marta, grupo focal).

Diante do feedback negativo dos estudantes quanto ao volume de atividades, a professora afirmou pretender implementar possíveis mudanças em uma nova edição do curso, reconhecendo que algumas propostas de atividades envolviam vários procedimentos interligados, o que lhes aumentava a complexidade e demandava mais tempo para execução:

Pretendo, em uma nova edição do curso, sobrecarregar menos os alunos, exigindo menos em termos de tarefas. No caso das tarefas, por exemplo, algumas vezes os alunos precisavam fazer uma tarefa, postar um arquivo e além disso comentar no fórum. Talvez só participar do fórum já seja suficiente, especialmente se a turma for composta de alunos com conhecimento intermediário ou avançado da língua (Professora, entrevista)

É importante, porém, frisar que a rejeição da maioria dos estudantes não se relacionou diretamente à utilização do componente on-line em si, mas à proporção de atividades realizadas à distância em relação às aulas presenciais, que foi diferente do proposto no início do curso.

Os foruns e as atividades foram bem interessantes mas seria bom se houvesse mais atividades feitas em sala ao invés de quase todas ficarem para o moodle (Marta, grupo focal)

Achei a proposta do Moodle boa, porém achei que foram muitas aulas nesta plataforma, o que me cansou um pouco. Gostaria que tívessemos tido mais aulas presenciais (Keila, grupo focal)

Como ponto negativo da disciplina, concordo com a Carmem, acho que a quantidade de aulas virtuais é muito grande. Na minha opinião, a maioria das aulas deveriam ser presenciais, com atividades em sala de aula valendo ponto (Amanda, grupo focal)

Os fóruns foram uma boa atividade. Mas ter tantas atividades obrigatórias on-line foi um pouco pesado (Aluno(a) que preferiu não se identificar, questionário)

Ter menos atividades obrigatórias no Moodle diminuiria o índice de faltas dos alunos, uma vez que é mais fácil lembrar de vir a aula do que entrar no site (Aluno(a) que preferiu não se identificar, questionário)

As docentes observaram algumas crenças atribuídas aos alunos no que se refere a práticas educacionais mais centradas na atuação do professor e nas quais o aluno exerce um papel menos ativo, que emergiram nos discursos dos participantes, conforme os seguintes exemplos: 
Os alunos de Biologia, segundo relataram, estão acostumados a irem para a sala de aula e os professores darem palestras. O professor fala, fala, fala, com aquele monte de slides, e os alunos têm uma quantidade gigantesca de material para estudarem para as provas nas quais serão aprovados ou reprovados. Quando percebem, em nosso caso, que terão que acessar o ambiente on-line para fazer atividades diferentes a cada tópico, há resistência, pois eles percebem que vão precisar trabalhar muito." (Professora, entrevista)

Neste período, os alunos já construíram um método próprio de aprendizado, quero dizer, no caso da biologia, os alunos já se acostumaram com as aulas massivas de conteúdo e com o decorar para a prova. E aí de repente vem uma disciplina em que a gente tem que ler toda semana alguma coisa, postar alguma coisa... é meio que um "choque" (Lara, grupo focal).

A dificuldade de gerir o tempo disponível para participar de um número significativo de atividades on-line ao longo do curso representou outro ponto de dificuldades para os estudantes. Diante da necessidade de melhor gerirem o tempo disponível para as atividades acadêmicas, fossem elas on-line, fossem elas presenciais, os alunos reconheceram que necessitavam desenvolver estratégias específicas de produtividade, como conseguir ler melhor e mais rápido. Paradoxalmente, os discentes também alegaram que a sobrecarga habitual de tarefas acadêmicas lhes impedia de investir tempo para desenvolverem tais competências:

Pois é, também tenho que renovar esse hábito de leitura! De fato ler é extremamente importante (Renata, fórum "Food for thought") (grifo do texto original)

Esse é justamente o problema, Renata. A faculdade já absorve tanto o nosso tempo, que sempre é difícil se libertar um pouco para se dedicar a outras coisas (Wilson, fórum "Food for thought", em resposta Renata).

É necessário ir muito mais além e desenvolvermos estratégias para melhor compreensão e aproveitamento do que estamos lendo ou estudando. É importante até para economizar tempo quando temos muita coisa para ler! (Amanda, grupo focal).

A prática da procrastinação de tarefas se revelou habitual por grande parte dos estudantes, fosse causada pela sobrecarga de atividades ou condicionada por determinantes culturais. Os sucessivos protelamentos levavam os estudantes a finalizarem as tarefas apenas nos últimos limites dos prazos estabelecidos, o que também dificultava o gerenciamento do próprio tempo e interferia negativamente na qualidade final do resultado da tarefa.

Se os alunos participam da aula on-line, ela tem o mesmo peso da aula presencial. Mas se eles demoram a entrar [no ambiente on-line] e fica aquela coisa muito corrida... Isso acontece muito com os prazos: o aluno deixa para entrar no último dia e se a interação é pelo fórum, precisa ter aquela discussão que não pode ser no 
último dia. (...) A maioria deixa as atividades para a última hora. Verificávamos na plataforma que a maioria dos alunos enviava as atividades duas horas antes do prazo final. E os prazos eram bem razoáveis, em média de dez dias de antecedência para cada atividade, por vezes estendidos até duas semanas (Monitora, entrevista).

Contudo, apesar dessas dificuldades relatadas pelos alunos quanto à gestão do tempo necessário às atividades digitais do curso, a professora do curso constatou que a maioria dos estudantes realizou as tarefas propostas com eficácia e dentro dos prazos solicitados, padrões característicos do engajamento do tipo comportamental que se relacionam prioritariamente a indicadores quantitativos de avaliação da aprendizagem.

Os alunos apresentaram bastante senso crítico e de responsabilidade, cumprindo com suas obrigações nos prazos propostos (Professora, entrevista).

\section{CONSIDERAÇÕES FINAIS}

Foi possível destacar, nos discursos dos participantes, fatores e aspectos envolvidos em seu engajamento nas interações no ambiente virtual de aprendizagem investigado. Estes foram organizados em favoráveis e desfavoráveis, conforme resumo abaixo:

\begin{tabular}{|l|l|}
\hline \multicolumn{1}{|c|}{$\begin{array}{c}\text { Fatores e aspectos } \\
\text { favoráveis ao engajamento }\end{array}$} & \multicolumn{1}{c|}{$\begin{array}{c}\text { Fatores e aspectos } \\
\text { desfavoráveis ao engajamento }\end{array}$} \\
\hline $\begin{array}{l}\text { Funcionalidades oferecidas pela } \\
\text { mediação digital. }\end{array}$ & Limitações decorrentes da mediação digital \\
\hline Interações entre estudantes e docentes & $\begin{array}{l}\text { Desequilíbrio entre on-line } \\
\text { e presencial }\end{array}$ \\
\hline Interações entre os estudantes & Interações sem mediação docente \\
\hline $\begin{array}{l}\text { Diversidade de formatos e de temas } \\
\text { abordados }\end{array}$ & $\begin{array}{l}\text { Grande volume e complexidade das } \\
\text { atividades on-line }\end{array}$ \\
\hline Avaliação contínua das atividades & $\begin{array}{l}\text { Dificuldade para gerenciamento do tempo } \\
\text { disponível }\end{array}$ \\
\hline
\end{tabular}

Tabela 1: Fatores e aspectos favoráveis e desfavoráveis ao engajamento

Ainda que condições consideradas comuns para o engajamento em contextos educacionais como relevância das atividades, participação ativa dos estudantes e variedade de recursos tecnológicos e de possibilidades de interações disponíveis estivessem presentes no meio on-line, o engajamento dos estudantes, principalmente no aspecto emocional, foi prejudicado pelo volume de atividades, considerado excessivo pelos participantes e por sua complexidade, em alguns casos. 
As interações aluno-professor ocorridas no AVA foram muito valorizadas pelos estudantes, que enfatizaram favoravelmente a constância da presença virtual da monitora e da professora, sendo possível considerar esse feedback positivo como um indicador de maior engajamento emocional por parte dos discentes em resposta à maior presença docente no ambiente digital. No entanto, os estudantes almejavam maior interação presencial com a docente responsável pelo curso, considerando que o número de aulas a distância superou o de aulas presenciais, diferentemente do previsto no início do período letivo, que previa um volume semelhante de aulas presenciais e à distância.

Embora os participantes tenham avaliado favoravelmente a diversidade de atividades apresentadas por meio do ambiente digital, as interações aluno-conteúdo propostas para o contexto on-line também foram consideradas excessivas e mais complexas do que seria adequado para a carga horária do curso, verificando-se aqui que esse descompasso entre a proposta docente para o curso e as expectativas dos estudantes pode ter concorrido para menor nível de engajamento cognitivo.

A respeito da interconexão entre os componentes on-line e presencial que constituíam o curso semipresencial em foco, é importante registrar que não foram ignoradas neste estudo as possíveis interferências das interações presenciais nas interações à distância. Porém, o significativo volume de aulas à distância na carga horária total do curso, e o elevado número de interações no ambiente virtual de aprendizagem, além do foco principal pressuposto para esta pesquisa, cujo escopo foram as interações no ambiente on-line do curso, justificaram a relevância da análise do contexto digital pensado em si mesmo, ainda que algumas questões relacionadas às interações presenciais também tenham vindo à tona e sido consideradas como parte da presente análise.

Tratando-se de um estudo de caso de perspectiva etnográfica, não se esperava que seus resultados pudessem estabelecer relações genéricas de causa ou efeito ou princípios necessariamente aplicáveis a contextos análogos. Buscou-se, ao invés disso, possibilitar reflexões e propor discussões sobre os elementos relacionados às interações e engajamento em ambientes virtuais de aprendizagem, de modo a contribuir para o aprimoramento da utilização desses espaços digitais e para o ensino semipresencial e à distância, de modo geral. Além disso, investigações dessa natureza, além de suscitar reflexões por parte do pesquisador-autor do trabalho, podem e devem convidar os demais participantes da pesquisa a direta ou indiretamente (re)pensarem criticamente suas próprias práticas (SCHÖN, 1983). 
Há ainda a expectativa de que a discussão do engajamento sob a perspectiva discente apresentada neste trabalho possa contribuir para que o tema venha a ser considerado com mais atenção quando da implementação de AVAs, tanto na modalidade semipresencial como naquela totalmente à distância. Constatando-se ainda que o tema engajamento em interações on-line em ambientes virtuais de aprendizagem ainda se encontra bastante ausente das investigações acadêmicas em nosso país, sugerese também que venha a ser objeto de outras investigações futuras.

Outras possibilidades de pesquisas ulteriores identificadas a partir do presente trabalho incluem a investigação das crenças e pressupostos dos estudantes a respeito do ensino semipresencial e da educação à distância no contexto do ensino superior. Novas pesquisas que focalizem tanto o ambiente on-line quanto o presencial de forma mais abrangente também são recomendadas, considerando-se que tal questão emergiu com intensidade no contexto analisado, não tendo sido investigada com mais profundidade pelas limitações do escopo da pesquisa.

\section{REFERÊNCIAS}

APPLETON, J. J.; CHRISTENSON, S. L.; FURLONG, M. J. Student engagement with school: Critical conceptual and methodological issues of the construct. Psychology in the Schools, v. 45, n. 5, p. 369-386, 2008.

APPLETON, J. J.; CHRISTENSON, S. L.; KIM, D.; RESCHLY, A. L . Measuring cognitive and psychological engagement: Validation of the Student Engagement Instrument. Journal of School Psychology Motivation. v. 44, n. 5, p. 427-445, out. 2006. Disponível em:

$<$ http://www.sciencedirect.com/science/article/pii/S0022440506000379>. Acesso em: 18 out. 2014.

ANDERSON, T. Modes of Interaction of Distance Education. In: MOORE, M.; ANDERSON, W. G. (Eds.). Handbook of Distance Education. Mahwah, N.J. : L. Erlbaum Associates, 2003. p. 129-144.

ANGROSINO, Michael V. Recontextualizing observation: Ethnography, pedagogy, and the prospects for a progressive political agenda. The Sage handbook of qualitative research. U.S., California: Sage, 2005. 3 v. p. 729-745.

ATWEH, B.; BLAND, D. C.; CARRINGTON, S. B.; CAVANAGH, R. School disengagement : its constructions, investigation and management. In: AARE INTERNATIONAL EDUCATION RESEARCH CONFERENCE. Anais... , 2007. Freemantle, WA. Disponível em: $<$ http://eprints.qut.edu.au/17737/1/c17737.pdf $>$. Acesso em: 24 maio 2014. 
BELLONI, M. L. Ensaio sobre a educação a distância no Brasil. Educação \& Sociedade, v. 23, n. 78, p. 117-142, 2002. Disponível em:

$<$ http://www.scielo.br/scielo.php?script=sci_arttext\&pid=S0101-

$73302002000200008 \& \operatorname{lng}=$ pt\&nrm=iso $\& \operatorname{tn} g=p t>$. Acesso em: 28 maio 2014.

CLAXTON, G. Expanding Young People's Capacity to Learn. British Journal of

Educational Studies, v. 55, n. 2, p. 115-134, 2007. Disponível em:

$<$ http://www.tandfonline.com/doi/abs/10.1111/j.1467-8527.2007.00369.x>. Acesso em: 10 maio 2014.

DUNLEAVY, J.; MILTON, P. A. What did you do in school today? Exploring the Concept of Student Engagement and its Implications for Teaching and Learning in Canada. Toronto: Canadian Education Association (CEA), 2009. Disponível em < http://www.cea-ace.ca/sites/cea-ace.ca/files/cea-2009-wdydist-concept.pdf>. Acesso em: 09 maio 2013.

FINN, J. D. Withdrawing From School. Review of Educational Research v. 59, n. 2, p. 117-142 , 1 jun. 1989. Disponível em: <http://rer.sagepub.com/content/59/2/117>. Acesso em: 12 maio 2014.

FLOYD, Kevin; HARRINGTON, Susan; SANTIAGO, Julie. Improving I.S. student Engagement and Perceived Course Value. SAIS 2009 Proceedings, 2009. Disponível em: < http://aisel.aisnet.org/sais2009/5>. Acesso em: 12 set. 2014.

FRAGOSO, S.; RECUERO, R.; AMARAL, A. Métodos de pesquisa para internet. 1. ed. Porto Alegre: Sulina, 2011.

FRANCO, C. de P. O uso de um ambiente virtual de aprendizagem no ensino de inglês: além dos limites da sala de aula presencial. Dissertação de Mestrado apresentada ao Programa Interdisciplinar de Pós-Graduação em Linguística Aplicada da Universidade Federal do Rio de Janeiro, Universidade Federal do Rio de Janeiro (UFRJ), Rio de Janeiro, 2009. Disponível em:

$<$ http://www.lingnet.pro.br/media/dissertacoes/katia/2009-claudio.pdf $>$. Acesso em: 15 maio 2014.

FREDRICKS, J. A.; BLUMENFELD, P. C.; PARIS, A. H. School Engagement: Potential of the Concept, State of the Evidence. Review of Educational Research, $v$. 74, n. 1, p. 59-109, 2004. Disponível em: <http://rer.sagepub.com/content/74/1/59>. Acesso em: 12 maio 2014.

HARRIS, L. R. A Phenomenographic Investigation of Teacher Conceptions of Student Engagement in Learning. Australian Educational Researcher, v. 35, n. 1, p. 57-79, 2008. Disponível em:

$<$ http://www.eric.ed.gov/ERICWebPortal/contentdelivery/servlet/ERICServlet?accno=E J793463>. Acesso em: 12 maio 2014.

LEFFA, V. J. Interação virtual versus interação face a face: o jogo de presenças e ausências. In: CONGRESSO INTERNACIONAL DE LINGUAGEM E INTERAÇÃO, 2005, São Leopoldo, RS. Anais... São Leopoldo, RS: UNISINOS, 2005. Disponível em: 
$<$ http://www.leffa.pro.br/textos/trabalhos/interacao_virtual_e_face.pdf $>$. Acesso em: 12 dez. 2012.

MEYER, D. K.; TURNER, J. C. Re-conceptualizing Emotion and Motivation to Learn in Classroom Contexts. Educational Psychology Review v. 18, n. 4, p. 377-390 , 1 dez. 2006. Disponível em: <http://link.springer.com/article/10.1007/s10648-006-90321>. Acesso em: 20 maio 2014.

MOODLE PTY LTD. About Moodle. Moodle 2.6 documentation. 2014. Disponível em: $<$ http://docs.moodle.org/26/en/About_Moodle\#Easy_to_use >. Acesso em: 18 jun. 2014.

NYSTRAND, M.; GAMORAN, A. Instructional discourse, student engagement, and literature achievement. Research in the Teaching of English p. 261-290 , 1991.

OBLINGER, D. G.; OBLINGER, J. L. Is it age or IT: first steps towards understanding the net generation. Educating the Net Generation. p.2.1-2.20, 2005. U.S.: Educause. Disponível em: $<$ http://www.educause.edu/ir/library/pdf/pub7101.pdf $>$. Acesso em: 10 maio 2014.

PARSONS, J.; TAYLOR, L. Student Engagement: What do we know and what should we do? Edmonton.: AISI University Partners - Alberta Education, 2011. Disponível em: $<$ http://education.alberta.ca/media/6459431/student_engagement_literature_review_201 1.pdf>. Acesso: 12 jun. 2014.

PATRICK, Helen; RYAN, Allison M.; KAPLAN, Avi. Early adolescents' perceptions of the classroom social environment, motivational beliefs, and engagement. Journal of Educational Psychology, v. 99, n. 1, p. 83-98, 2007.

PRENSKY, M. Digital Natives, Digital Immigrants Part 1. On the Horizon. v. 9, n. 5, p. 1-6, 9 jan. 2001. Disponível em:

$<$ http://www.marcprensky.com/writing/prensky\%20-

$\% 20$ digital\%20natives, \%20digital\%20immigrants\%20-\%20part1.pdf $>$. Acesso em: 17 jan. 2013.

REEVE, Johnmarshall. A Self-determination Theory Perspective on Student Engagement. In: CHRISTENSON, Sandra L.; RESCHLY, Amy L.; WYLIE, Cathy (Orgs.). Handbook of Research on Student Engagement. U.S.: Springer US, 2012, p. 149-172. Disponível em: <http://link.springer.com/chapter/10.1007/978-1-46142018-7_7>. Acesso em: 3 jan. 2015.

RUDDUCK, J. Student Voice, Student Engagement, And School Reform. In: THIESSEN, D.; COOK-SATHER, A. (Eds.); International Handbook of Student Experience in Elementary and Secondary School. p.587-610, 2007. Springer Netherlands. Disponível em: <http://www.springerlink.com/content/978-1-4020-33667/\#section=276074\&page $=1 \&$ locus $=0>$. Acesso em: 25 maio 2014.

SCHÖN, D. A. The Reflective Practitioner: How Professionals Think in Action. U.S.: Basic Books, 1983. 
TAVARES, K. C. do A. Projeto LingNet - Letras2.0. Disponível em: $<$ http://www.lingnet.pro.br/pages/letras2.0.php\#axzz2ODJOw24x>. Acesso em: 6 maio 2014.

TROWLER, Vicki. Student engagement literature review. York, U.K.: The Higher Education Academy, 2010. Disponível em: <http://wwwnew2.heacademy.ac.uk/assets/documents/studentengagement/StudentEngagementLitera tureReview.pdf>. Acesso em: 5 jan. 2015.

YIN, Robert K. Case study research: design and methods. U.S.: SAGE, 2009

ZYNGIER, D. (Re) conceiving Student Engagement: What the Students Say They Want. Putting Young People at the Centre of the Conversation. Student Engagement in the 21st Century, v. 1, n. 1, p. 93-116, 2007. Disponível em:

$<$ http://www.learnquebec.ca/en/content/learninglandscapes/voll no1.html $>$. Acesso em: 9 set. 2014.

\section{A AUTORA}

Luciana Nunes Viter é graduada em Letras (FERLAGOS), especialista em Informática na Educação (UFLA) e em Tradução Inglês-Português (UGF), mestra e doutoranda em Linguística Aplicada (UFRJ). Atualmente exerce as funções de assessora do Projeto Letras 2.0 (LingNet/UFRJ) e professora de Língua Inglesa (FAETEC). Seus temas de pesquisa, centrados nos relacionamentos entre cibercultura e aprendizagem, incluem o engajamento no uso de ambientes virtuais e a produção de textos e a formação de leitores em contextos digitais.

E-mail: lucianaviter@ufrj.br 